\title{
Valuation of traits of indigenous sheep using hedonic pricing in Central Ethiopia
}

\author{
Zelalem G Terfa ${ }^{1 *}$, Aynalem Haile ${ }^{2}$, Derek Baker ${ }^{3}$ and Girma T Kassie ${ }^{4}$
}

\footnotetext{
*Correspondence: zedgutu@gmail. com

${ }^{1}$ The University of Liverpool, Liverpool, UK

Full list of author information is available at the end of the article
}

\begin{abstract}
This study estimates the implicit prices of indigenous sheep traits based on revealed preferences. A hedonic pricing model is fitted to examine the determinants of observed sheep prices. Transaction data were generated from rural markets of Horro-Guduru Wollega Zone of Ethiopia. Both OLS and heteroscedasticity consistent estimations were made. The empirical results consistently indicate that phenotypic traits of traded indigenous sheep (age, color, body size, and tail condition) are major determinants of price implying the importance of trait preferences in determining the price of sheep in local markets. Season and market locations are also very important price determinants suggesting the need to target season and market place in sheep improvement programmes. Therefore, the development of a comprehensive breeding program that has marketing element is crucial to make sheep improvement sustainable and sheep keepers benefit from the intervention.
\end{abstract}

Keywords: Hedonic pricing; Heteroscedasticity consistent; Phenotypic; Indigenous; Trait preference

\section{Background}

Small ruminants are a key component of the rural livelihood systems in rural Ethiopia. It is estimated that in 2010 Ethiopia owned about 48 million small ruminants (FAOSTAT, 2010) and this is one of the largest populations in sub Saharan Africa (SSA). Small ruminants contribute substantially to income, food (meat and milk), and non-food products like manure, skins and wool. They also serve as part of the crop failure risk coping portfolio of enterprises, for asset wealth security as form of money saving and investment as well as many other cultural functions (Tibbo, 2006). At farm household level, sheep contribute up to $63 \%$ of the net cash income derived from livestock production in the crop-livestock production systems in Ethiopia. In the dry lowlands of the country, sheep play a key role in sustaining the livestock-based pastoral and agro-pastoral livelihoods (Negassa and Jabbar, 2008). Despite the pronounced importance of small ruminants in general and sheep in particular, the productivity of the animals per head is considerably low. FAO (2009) estimated the average annual off-take rate and carcass weight per slaughtered animal for the period 2000 to 2007 to be $32.5 \%$ and $10.1 \mathrm{~kg}$, respectively, the lowest even among the sub Saharan African countries. In fact, in the highlands of the country, sheep off-take was found to be even lower at 7\% (Negassa and Jabbar, 2008).

(C) 2013 Terfa et al.; licensee Springer. This is an Open Access article distributed under the terms of the Creative Commons Attribution License (http://creativecommons.org/licenses/by/2.0), which permits unrestricted use, distribution, and reproduction in any medium, provided the original work is properly cited. 
In the study area (Horro-Guduru Wollega Zone of Ethiopia) sheep are equally important in the rural economy. The sheep production systems in the area, however, are traditional and semi-subsistence oriented. So far, only very limited efforts have been exerted to introduce and promote market-oriented sheep production and hence the current income generating capacity of the sector is not at all justifiable. Re-orientation of the production system, which involves designing an effective and informed breeding programme, is a necessity to bring about improvements in productivity and in the production system of the sector. This re-orientation entails proper valuation of both traded and non-traded products and services generated from the system. Information on the economic value of populations, traits and processes would ease the management of animal genetic resources that requires many decisions (Scarpa et al. 2003). Proper identification and valuation of the different characteristics would make resource allocation decisions among the different livestock improvement interventions for commercialization of the system quite fast and smooth (Drucker et al. 2001; Kassie, 2007). This will also enable identification of sheep market opportunities by identifying preferred traits of sheep. This is crucial as consumers' demand and preference is continuously changing over time.

Researchers have applied different economic valuation methods to understand the preference for and the value of animal traits in different contexts. Revealed preference and stated preference based models are the two most commonly used approaches. Revealed preferences based valuation methods record and analyze actual payments on observable transactions for the commodities/services of interest while stated preference based valuation methods make use of data on hypothetical choices and implicit payments (Hensher et al. 2005). Richards and Jeffrey (1996) employed a hedonic pricing model to establish indices of genetic worth of a dairy bull in Alberta, Canada. Their study indicated that the most important factors used by dairy farmers in valuing dairy bulls are milk volume, protein and fat content, general conformation, body capacity, and popularity of the bull. Barret et al. (2003) used a structural-heteroskedasticity-inmean estimation method to identify the determinants of livestock producer prices in the dry lands of northern Kenya. Their result shows the importance of animal characteristics, periodic events that shift local demand or supply, and rainfall in determining prices producers receive. Williams et al. (2006), similarly used a hedonic model using weekly sales transactions to analyze cattle prices in West Africa and reported that location, season, and cattle attributes influence sheep price.

In their study that aimed at investigating determinants of inter-annual price variation of small ruminants' price in the eastern highlands of Ethiopia, Gezahegn et al. (2006) employed hedonic price modeling and reported significant differences in prices between seasons and markets, controlling for attributes of animals. Kassie et al. (2011a) similarly applied heteroscedasticity consistent hedonic price modeling to examine factors that influence cattle prices in the rural markets of central Ethiopia. The results of this study showed that season, market location, age, sex and body size are very important determinants of cattle price. Chang et al. (2010) employed hedonic price modeling to study price differentials of retailed eggs and reported significant premiums attributed to production method, variation in geographic locations and egg color. Similarly, Satimanon and Weatherspoon (2010) employed the same approach to determine price premiums of traits of fresh eggs using sustainable attribute data from retail markets in 
the United States. Their study indicates that welfare-managed eggs have a significant price premium while the sustainable packaging attributes are insignificant.

Other studies used a combination of revealed and stated preference data (e.g., Scarpa et al. 2003; Kassie et al. 2011b). Stated preference based valuation of animal genetic resources has also been widely used (e.g., Omondi et al. 2008; Kassie et al. 2009, and Faustin et al. 2010). In recent years there is a growing interest in using stated preference approaches which specifically employ choice experiments as real choice data in actual market are hardly available. Whenever available, however, revealed preference data have obvious advantages over stated preference data. Real world representation, embodiment of real constraints, reliability and validity are advantages of revealed preference data (Haab and McConnel, 2002; Hensher et al. 2005).

This brief review has shown that there is an enormous body of knowledge on the relevance and application of hedonic price models. Although the focus of most of the studies is market oriented production systems, the importance of the attributes of livestock in determining prices observed in the market is a key lesson to learn. Interestingly though, there are hardly any publications done on sheep price modeling in subsistence and/or semi-subsistence crop livestock mixed farming systems. This research employs the well-established hedonic price modeling in a context where markets are yet to develop and sheep have a more complex role than serving simply as sources of meat or in some cases wool.

\section{Methods}

\section{The study area and the rural markets}

The study was conducted in the Horro-Guduru Wollega zone of Ethiopia. The administrative capital of the zone is called Shambu and is located at about $310 \mathrm{~km}$ west of Addis Ababa. The 2007 population and housing census of the Central Statistical Agency showed that in 2007 the total population of the zone was about 580,000 out of which $50.1 \%$ were male and $49.9 \%$ were female (CSA, 2007). About $89 \%$ of the population in the zone lived in rural areas. The total area of the zone is about 710,000 hectares. According to the agency's national agricultural survey, the livestock population of the zone encompassed 127,000 heads of cattle, 25,000 sheep, and 12,000 goats (CSA, 2009).

The study covered four sheep markets, namely, the markets of Shambu, Gaba Sanbata, Harato, and Fincha. All the markets, except Shambu, are weekly markets that set on once in a week on a designated day. Shambu operates throughout the week, except on Sundays. The market infrastructure in the zone is very poor and there is no fence or shed, information provision, and feed provision in these four markets. Fincha is the only fenced sheep market where livestock are traded in a relatively organized manner. Livestock are trekked to and from all the markets. The study markets are among the remote rural markets dominated by (crop and livestock) farmers, farmertraders, peri-urban butchers and small restaurant owners.

In these markets, grading and standardization do not exist and transactions take place after a long one-to-one bargaining between sellers and buyers on a per-head basis. The price paid by the buyer and received by the seller, therefore, depends, among others, on how well he or she can bargain. Under such circumstances, prices paid will reflect buyers' preference for various sheep traits, the type of buyer and seller and characteristics of the market place. The identification and analysis of the preferred traits 
and household characteristics that influence the prices actually paid in the market accordingly forms the basis for effective market development interventions. This study generated primary data and analyzed the factors that determine sheep prices in rural parts of the zone for this particular purpose.

\section{The data}

Data on 195 traded sheep and on sheep marketers' attributes were collected in the four rural sheep markets mentioned above. The main traits of traded sheep we focused on were coat color, body size, tail condition, age, and sex. Markets in developing countries in general and in such rural setups in particular are hardly competitive due to the sources of inefficiency mentioned above and all other generic sources of market imperfections. This entails the inclusion of factors apart from the attributes of the goods and services - in this case the sheep - in the model specification (Abdulai 2000; Kassie et al. 2011a). Therefore, we have generated and analyzed data on other factors that are expected to affect sheep price. These factors include the attributes of buyers and sellers, such as occupation and education level to serve as proxies for bargaining power. Seasonality of demand and supply was also captured. Description of variables used in this study is presented in Table 1 below.

Three survey rounds of individual sheep level transactions were conducted over an interval of one month. The first round was conducted during the beginning of January 2009; i.e., the Ethiopian Christmas season. This round was targeted to capture the price change that occurs during holidays. The second round was done in February 2009. This is a period with no important festival or planned social occasion and it overlaps with the time when farmers have completed crop harvesting. By this time farmers are expected to be less forced to sell their livestock for generating liquid capital (Kassie et al. 2011a). The third round was undertaken in March 2009. This period corresponds to the Ethiopian lent. From each market, 15 buyers were considered in each round except in Harato where 20 buyers were interviewed, taking into account the relative size of the market. That means 65 buyers were interviewed in each round.

The descriptive statistics of the variables used in the econometric model show considerably variation across respondents (Table 2). The average age of marketed sheep in the surveyed rural markets was one year (st.dev. $=11.4$ months). In the observed sheep transactions in the four markets, $59 \%$ of traded sheep were male implying that female sheep are less frequently marketed as they are usually kept for reproduction (herd replacement) and less for generating cash. The average sheep price during this study was more than Ethiopian Birr 238.00. Sheep in those markets were observed to have different patterns of fur color although red was the dominant color (44\%) followed by creamy-white (29\%) over the survey period and observed transactions. More than $10 \%$ of the marketed sheep were black while the remaining were brown, white and mixed colored sheep. Data on body condition of the marketed sheep, which indicates relative fatness and appearance, were also observed and it was found that $48 \%$ of the sheep in the markets were in good condition and another $48 \%$ had a medium body condition. The remaining 3.6\% were sheep with bad body condition. Related is the body size of the sheep marketed and $43 \%$ of them were medium sized, $33 \%$ small and the rest large size. The dominant tail condition of the traded sheep were long and thin tail type (48\%) followed by long and fat tail type (24\%). Most actors in the local sheep markets 
Table 1 Summary of variables and coding method used in hedonic price model

\begin{tabular}{|c|c|c|c|}
\hline Attribute & Code & Attribute & Code \\
\hline Color & & Market place & \\
\hline \multirow[t]{3}{*}{ White } & 1 = white & Gaba sanbata & $1=$ Gaba sanbata \\
\hline & $-1=$ red & & $-1=$ Shambu \\
\hline & $0=$ otherwise & & $0=$ otherwise \\
\hline \multirow[t]{3}{*}{ Black } & $1=$ black & Fincha & $1=$ Fincha \\
\hline & $-1=$ red & & $-1=$ Shambu \\
\hline & $0=$ otherwise & & $0=$ otherwise \\
\hline \multirow[t]{3}{*}{ Brown } & $1=$ brown & Harato & $1=$ Harato \\
\hline & $-1=$ red & & $-1=$ Shambu \\
\hline & $0=$ otherwise & & $0=$ otherwise \\
\hline \multirow[t]{3}{*}{ Creamy white } & $1=$ creamy white & Seller type & \\
\hline & $-1=$ red & Farmer & 1 = farmer \\
\hline & $0=$ otherwise & & $-1=$ trader \\
\hline \multirow[t]{3}{*}{ White mixed } & $1=$ white mixed & & $0=$ otherwise \\
\hline & $-1=$ red & Farmer trader & $1=$ farmer trader \\
\hline & $0=$ otherwise & & $-1=$ trader \\
\hline \multirow[t]{2}{*}{ Sex of sheep } & 0 - female & & $0=$ otherwise \\
\hline & 1 - male & Buyer type & \\
\hline Body size & & Trader & $1=$ buyer is trader \\
\hline \multirow[t]{3}{*}{ Medium size } & $1=$ medium & & $-1=$ other buyers \\
\hline & $-1=$ small & & $0=$ otherwise \\
\hline & $0=$ otherwise & Farmer & $1=$ buyer is farmer \\
\hline \multirow[t]{3}{*}{ Big } & $1=$ big & & $-1=$ other buyers \\
\hline & $-1=$ small & & $0=$ otherwise \\
\hline & $0=$ otherwise & Farmer trader & 1 - buyer is farmer trader \\
\hline Tail type & & & $-1=$ other buyers \\
\hline \multirow[t]{3}{*}{ Medium and thin } & $1=$ medium and thin & & $0=$ otherwise \\
\hline & $-1=$ long and fat & Season & \\
\hline & $0=$ otherwise & Christmas (season 1) & $1=$ Christmas \\
\hline \multirow[t]{5}{*}{ Medium and fat } & $1=$ medium and fat & & $-1=$ season 2 \\
\hline & $-1=$ long and fat & & $0=$ otherwise \\
\hline & $0=$ otherwise & Fasting (season 3) & $1=$ fasting season \\
\hline & & & $-1=$ season 2 \\
\hline & & & $0=$ otherwise \\
\hline
\end{tabular}

were farmers and sheep traders. Though data on the qualitative attributes were entirely based on buyers' perception of traded sheep, it is important to understand buyers' preference for these attributes. Generally, the typical sheep traded in these markets is 12 months old, red coated, of good or medium body condition, medium body size, and long thin tailed.

\section{Analytical framework}

Revealed preference is manifested through the actual prices paid for goods and services with expected utility. Hence, the prices sheep sellers receive are reflections of the utility 
Table 2 Descriptive statistics for sheep in the local market and market participants

\begin{tabular}{|c|c|}
\hline Description & Mean(SD)/percentage \\
\hline Price per head of sheep $\left(\mathrm{ETB}^{*}\right)$ & $238.36(83.92)$ \\
\hline Age of sheep in months & $12(11.431)$ \\
\hline Male sheep (\%) & 58.5 \\
\hline \multicolumn{2}{|l|}{ Sheep coat color (\%) } \\
\hline Red & 44.1 \\
\hline Creamy white & 28.7 \\
\hline Black & 10.3 \\
\hline Brown & 3.1 \\
\hline White & 4.6 \\
\hline White mixed with other colors & 9.2 \\
\hline \multicolumn{2}{|l|}{ Body condition (\%) } \\
\hline Good & 48.2 \\
\hline Medium & 48.2 \\
\hline Bad & 3.6 \\
\hline \multicolumn{2}{|l|}{ Body size (\%) } \\
\hline Small & 32.8 \\
\hline Medium & 42.6 \\
\hline Large & 24.6 \\
\hline \multicolumn{2}{|l|}{ Tail condition (\%) } \\
\hline Long fat tail & 24.1 \\
\hline Long thin tail & 47.7 \\
\hline Medium length thin tail & 14.9 \\
\hline Medium length fat tail & 13.3 \\
\hline \multicolumn{2}{|l|}{ Buyers' occupation (\%) } \\
\hline Trader & 41 \\
\hline Farmer & 10.8 \\
\hline Farmer-trader & 6.2 \\
\hline Others & 42.1 \\
\hline \multicolumn{2}{|l|}{ Sellers' occupation (\%) } \\
\hline Trader & 12.8 \\
\hline Farmer & 61 \\
\hline Farmer-trader & 13.8 \\
\hline Others & 12.4 \\
\hline
\end{tabular}

*ETB stands for Ethiopian Birr which is the Ethiopian currency.

anticipated by the buyers and this utility is derived from the attributes of the product as sheep can be considered as quality (attribute) differentiated goods (Lancaster, 1966; Rosen, 1974; Ekeland et al. 2004; Nesheim, 2006). This research focuses on the main phenotypic attributes that buyers inspect when buying a sheep. The external features farmers look at and attach value to are age, fur color, body size, and tail type. The different levels of the homogenous attributes that differentiate sheep are known to both buyers and sellers. The levels considered in this analysis are those perceived by the buyers, despite the possibility of imperfect knowledge and differences in measurement. The buyers and sellers in the markets considered are mainly farmers who raise the sheep. In line with the household modeling literature, where goods are produced, 
consumed and sold by households, a hedonic model can be employed to value the attributes of the quality differentiated indivisible goods. Therefore, estimation of the relationship between the characteristics of the sheep and their prices can be made through hedonic price modeling.

Following Rosen (1974) and Palmquist (2006), let $x_{0 j}$ be the total amount of the $j^{\text {th }}$ product characteristic provided to the consumer by consumption of all products, $x_{i j}$ be the quantity of the $j^{\text {th }}$ characteristic provided by one unit of product $i$, and $q_{i}$ be quantity of the $i^{\text {th }}$ product consumed. Then, the total consumption of each characteristic can be given as

$$
x_{0 j}=f_{i}\left(q_{1}, \ldots, q_{n} ; x_{1 j}, \ldots, x_{n j}\right)
$$

and the consumer's utility function is expressed as

$$
U=\left(q_{1}, . . q_{n} ; x_{11}, x_{12}, . ., x_{1 m}, x_{21}, x_{22}, ., x_{n m}\right)
$$

where $\boldsymbol{n}$ is the number of products and $\boldsymbol{m}$ is the number of characteristics.

The consumer is assumed to maximize this utility function subject to a budget constraint that can be specified as

$$
Y=\sum_{i} \boldsymbol{p}_{i} \boldsymbol{q}_{\boldsymbol{i}}
$$

where $\boldsymbol{Y}$ is fixed money income, and $p_{i}$ is fixed price paid for the $i^{\text {th }}$ product. The consumer's utility maximizing level quantity of each product can then be estimated by maximizing the Lagrangian:

$$
\boldsymbol{L}=\boldsymbol{U}\left(\boldsymbol{x}_{01}, . ., \boldsymbol{x}_{0 n}\right)-\lambda\left(\sum_{i} \boldsymbol{p}_{i} \boldsymbol{q}_{i}-\boldsymbol{Y}\right)
$$

where $\lambda$ is the Lagrangian multiplier.

Assuming an interior solution, the first-order condition of the Lagrangian for $q_{i}$ is given as

$$
\frac{\partial \boldsymbol{L}}{\partial \boldsymbol{q}_{i}}=0=\sum\left(\frac{\partial \boldsymbol{U}}{\partial \boldsymbol{x}_{0 j}}\right)\left(\frac{\partial \boldsymbol{x}_{0 j}}{\partial \boldsymbol{q}_{i}}\right)-\lambda \boldsymbol{p}_{i}
$$

It can easily be shown that $\lambda$ is equal to the marginal utility of income $(\partial U / \partial Y)$. Substituting $\partial U / \partial Y$ for $\lambda$ and solving for $\boldsymbol{p}_{i}$, equation (5) can be rewritten in order to express the demand for attributes as a function of the marginal utility of the attribute and the marginal utility of income.

$$
p_{i}=\sum\left(\frac{\partial x_{0 j}}{\partial q_{i}}\right)\left[\frac{\left(\frac{\partial U}{\partial x_{0 j}}\right)}{\left(\frac{\partial U}{\partial Y}\right)}\right] \text {. }
$$

As income is defined to be equal to expenditure (equation 4), the term in the square bracket is the marginal rate of substitution between expenditure and the $j^{\text {th }}$ product characteristics.

Under competitive market conditions, implicit prices will normally be related to product attributes alone, without accounting for producer or supplier attributes. However, as widely documented in the literature, rural markets in developing countries, particularly in sub-Saharan Africa, are rarely competitive (Barret and Mutambatsere 2007). 
This is essentially due to poor communication and transport infrastructure, limited rule of law, and restricted access to commercial finance, all of which make markets function much less effectively. Several empirical studies have shown that prices are also related to the attributes of buyers, season and market location (e.g., Oczkowski, 1994; Abdulai, 2000; Jabbar and Diedhiou, 2003). Hence, essential characteristics of the buyer and sellers were included in the models estimated in this research.

Another important issue in estimating hedonic functions is the identification of the appropriate functional form and estimation procedure (Ekeland et al. 2004; Nesheim, 2006). In general, the functional form of the hedonic price equation is unknown (Haab and McConnel, 2002). Parametric, semi-parametric and non-parametric estimations procedures have all been suggested and used in different applications (e.g., Anglin and Gencay, 1996; Parmeter et al. 2007). This research focuses on the estimation of the relative weights of sheep attributes (first step hedonic analysis) and hence the technical details of these alternative approaches are not discussed.

The estimation strategy adopted in this study is a simple linear model based following the suggestion by Cropper et al. (1988) as well as Haab and McConnel (2002). Cropper et al. (1988) employed Monte-Carlo simulation analysis to show that the linear and linear-quadratic functions give the smallest mean square error of the true marginal value of attributes. However, when some of the regressors are measured with error or if a proxy variable is used, then the linear function gives the most accurate estimate of the marginal attribute prices. Haab and McConnel (2002) also argued that when choosing a functional form and the set of explanatory variables, the researcher must bear in mind the almost inevitable conflict with collinearity. High collinearity makes the choice of a flexible functional form less attractive, since the interactive terms of a flexible functional form result in greater collinearity. Given these considerations, we begin with semi-log model given by

$$
\ln (\text { price })=X \boldsymbol{\beta}+\boldsymbol{\varepsilon} .
$$

Following Champ et al. (2003), the market premium $(\Gamma)$ for an attribute $j$ is computed as:

$$
\Gamma_{j}=100^{*}\left(e^{\beta}-1\right) .
$$

In equation (7) the error term is assumed to have a constant variance, $\sigma^{2}$; hence, homoscedastic. However, if and when the errors are heteroscedastic, the OLS estimator remains unbiased, but becomes inefficient. More importantly, the usual procedures for hypothesis testing are no longer appropriate. Given that heteroscedasticity is common in small sample cross-sectional data, methods that correct for heteroscedasticity are essential for prudent data analysis (Long and Ervin, 2000).

Using heteroscedasticity consistent $(\mathrm{HC})$ standard errors is the recommended approach (MacKinnon and White, 1985; Long and Ervin, 2000) to correct for heteroscedaticity of unknown form. The suggested alternative ways of correction using $\mathrm{HC}$ include $\mathrm{HC}_{0}, \mathrm{HC}_{1}, \mathrm{HC}_{2}$, and $\mathrm{HC}_{3}$. These alternatives are not equally powerful and perform differently under different conditions depending mainly on sample size. Based on Monte Carlo simulation, MacKinnon and White (1985), for example, recommended that in small samples one should use $\mathrm{HC}_{3}$. However, Davidson and MacKinnon (1993) later recommended strongly that $\mathrm{HC}_{2}$ or $\mathrm{HC}_{3}$ should be used. Long and Ervin (2000), 
similarly, recommended for $\mathrm{N} \leq 250$, tests based on $\mathrm{HC}_{2}$ and $\mathrm{HC}_{3}$ than those based on other $\mathrm{HC}$. This Monte Carlo simulation result also shows $\mathrm{HC}_{3}$ is superior for tests of coefficients that are most affected by heteroscedasticity and $\mathrm{HC}_{2}$ is better for tests of coefficients that are least affected by heteroscedasticity. Accordingly, we have employed $\mathrm{HC}_{2}$ and $\mathrm{HC}_{3}$ in this study. OLS was also applied for comparison.

Following Davidson and MacKinnon (1993), the alternative covariance matrix estimators of the error term for $\mathrm{HC}_{2}$ and $\mathrm{HC}_{3}$, including the OLS, are specified as:

$$
\begin{aligned}
& O L S=\frac{\sum \boldsymbol{e}_{i}^{2}}{\boldsymbol{n}-\boldsymbol{k}}\left(X^{\prime} X\right)^{-1} \\
& H C_{2}=\left(X^{\prime} \boldsymbol{X}\right)^{-1} X^{\prime} \operatorname{diag}\left[\frac{\boldsymbol{e}_{i}^{2}}{1-\boldsymbol{h}_{i i}}\right] X\left(X^{\prime} \boldsymbol{X}\right)^{-1} \\
& H C_{3}=\left(X^{\prime} X\right)^{-1} X^{\prime} \operatorname{diag}\left[\frac{\boldsymbol{e}_{i}^{2}}{\left(1-\boldsymbol{h}_{i i}\right)^{2}}\right] X\left(X^{\prime} X\right)^{-1}
\end{aligned}
$$

where $\boldsymbol{n}$ is number of observations, $\boldsymbol{k}$ number of parameters estimated, and $\boldsymbol{h}_{\boldsymbol{i} \boldsymbol{i}}$ is $\boldsymbol{x}_{i}^{\prime}$ $\left(\boldsymbol{X}^{\prime} \boldsymbol{X}\right)^{-1} \boldsymbol{x}_{i}$.

\section{Results and discussions}

\section{General model results}

The results of the hedonic price model from both OLS and $\mathrm{HC}$ regressions are given in Table 3. The table summarizes the coefficients of the variables used in the model, and the standard errors of OLS and heteroscedasticity consistent $\left(\mathrm{HC}_{2}\right.$ and $\left.\mathrm{HC}_{3}\right)$ estimations. HC estimation was used as an adjustment to the OLS model since crosssectional and small sample price data are intrinsically heteroscedastic. As expected, the OLS standard errors were found to be generally lower than the standard errors of $\mathrm{HC}_{2}$ and $\mathrm{HC}_{3}$ for all variables except for some variables in $\mathrm{HC}_{2}$. However, the standard errors of all explanatory variables in $\mathrm{HC}_{3}$ were increased and greater than both OLS and $\mathrm{HC}_{2}$ except for three variables brown, thin long tail condition, and sex. Hence, the $\mathrm{t}$-values of the OLS coefficients are inflated and could not be reliable for inferences. Between $\mathrm{HC}_{2}$ and $\mathrm{HC}_{3}$, the standard errors in $\mathrm{HC}_{2}$ were found to be lower than that of $\mathrm{HC}_{3}$. Therefore, the $\mathrm{t}$-values based on standard errors generated by $\mathrm{HC}_{3}$ estimation were used for inferences.

Due to the changes in standard errors in the three regression results, significant variables in OLS become insignificant and the significance levels of the variables have also been changed in $\mathrm{HC}_{2}$ and $\mathrm{HC}_{3}$. Age square was significant at $5 \%$ in OLS but the significance level in $\mathrm{HC}_{2}$ and $\mathrm{HC}_{3}$ changed to $10 \%$. Similarly, farmer trader (one of the buyer types) was significant at $5 \%$ in OLS, but in $\mathrm{HC}_{2}$ and $\mathrm{HC}_{3}$ the variable was significant only at $10 \%$. White mixed coat color, was significant at $1 \%$ in OLS but it became significant only at $5 \%$ in $\mathrm{HC}_{2}$ and $\mathrm{HC}_{3}$. Further, the variable representing trader buyer was significant in $\mathrm{OLS}$ and $\mathrm{HC}_{2}$ but became insignificant in $\mathrm{HC}_{3}$ estimation.

A model specification test was carried out for the OLS regression model using the Ramsey RESET test. The test with the (null) hypothesis that the model has no omitted variables generated an F $(3,161)$ value of 0.64 which is extremely below the critical value of 2.65 at $\alpha=0.05$ implying non-rejection of the hypothesis that there are no 
Table 3 Estimation results of OLS and Heterosecdasticity consistent hedonic model

\begin{tabular}{|c|c|c|c|c|}
\hline In(price) & Coefficient & $O L S S E$ & $H C 2 S E$ & $H C 3 S E$ \\
\hline Constant & $5.2350^{\ddagger}$ & 0.0729 & 0.0725 & 0.0812 \\
\hline \multicolumn{5}{|l|}{ Age and sex } \\
\hline Age & $0.0208^{\ddagger}$ & 0.0068 & 0.0067 & 0.0076 \\
\hline Age square & $-0.0003^{*}$ & 0.0001 & 0.0001 & 0.0002 \\
\hline Sex & -0.0457 & 0.0386 & 0.0346 & 0.0372 \\
\hline \multicolumn{5}{|l|}{ Coat color } \\
\hline White & -0.1003 & 0.0664 & 0.0965 & 0.1098 \\
\hline Brown & 0.0158 & 0.0829 & 0.0615 & 0.0696 \\
\hline Black & $-0.1614^{\ddagger}$ & 0.047 & 0.0488 & 0.0535 \\
\hline White mixed & $0.1305^{\dagger}$ & 0.0502 & 0.0515 & 0.0563 \\
\hline Creamy white & $0.0611^{*}$ & 0.0339 & 0.033 & 0.0362 \\
\hline \multicolumn{5}{|l|}{ Body Size } \\
\hline Medium & 0.034 & 0.0247 & 0.0247 & 0.0266 \\
\hline Large & $0.1467^{\ddagger}$ & 0.0414 & 0.0396 & 0.0429 \\
\hline \multicolumn{5}{|l|}{ Tail condition } \\
\hline Long thin & $-0.0831^{\ddagger}$ & 0.026 & 0.0236 & 0.0257 \\
\hline Medium \& thin & $-0.1225^{\ddagger}$ & 0.0337 & 0.0342 & 0.0373 \\
\hline Medium \& fat & 0.0319 & 0.0496 & 0.0406 & 0.0454 \\
\hline \multicolumn{5}{|l|}{ Season } \\
\hline Season 1 & $0.0769^{\ddagger}$ & 0.0226 & 0.0223 & 0.0239 \\
\hline Season 3 & -0.0275 & 0.0236 & 0.025 & 0.0268 \\
\hline \multicolumn{5}{|l|}{ Market/place } \\
\hline Finchaa & -0.0068 & 0.0309 & 0.0314 & 0.0336 \\
\hline G/sanbata & 0.0152 & 0.0306 & 0.0324 & 0.0344 \\
\hline Harato & $-0.0663^{\dagger}$ & 0.0286 & 0.028 & 0.0303 \\
\hline \multicolumn{5}{|l|}{ Type of seller } \\
\hline Farmer & -0.0041 & 0.0262 & 0.0267 & 0.0293 \\
\hline Farmer trader & 0.0116 & 0.0375 & 0.0356 & 0.0391 \\
\hline Others & -0.001 & 0.0417 & 0.0472 & 0.0518 \\
\hline \multicolumn{5}{|l|}{ Type of buyer } \\
\hline Trader & 0.0478 & 0.028 & 0.0276 & 0.0302 \\
\hline Farmer & 0.021 & 0.041 & 0.039 & 0.0423 \\
\hline Farmer trader & $-0.1042^{*}$ & 0.0506 & 0.0563 & 0.0631 \\
\hline
\end{tabular}

$\neq, \dagger$ and ${ }^{*}$ significant at $\mathrm{a}=0.01, \mathrm{a}=0.05$ and $\mathrm{a}=0.1$ respectively, based on $\mathrm{HC}_{3}$ standard errors. $\mathrm{SE}=$ standard error. Number of observations $=195, R^{2}=0.6887$.

omitted relevant explanatory variables. The R-square value of the models is $0.6887 \mathrm{im}$ plying that the model explained about $69 \%$ of change in price of sheep in the local markets of Horro-Guduru Wollega zone of Ethiopia.

\section{Determinants of price and premium for indigenous sheep traits}

The results of the three estimations (OLS, $\mathrm{HC}_{2}$ and $\mathrm{HC}_{3}$ ) show that sheep price is determined by sheep traits (such as age, color, body size, and tail condition), season, market places, and buyer type. Age significantly and positively influenced price of sheep in 
the study area. This is in line with the basic feature of the low input sheep production system in the area. That is, under a low input production system sheep need a longer period of time to attain the required body condition and size to command a good price. Age square, however, influenced sheep price negatively implying sheep command a higher price up to a very old age and then the price will fall down as age goes up. Given the weight of the coefficient and the average age of sheep being marketed, it seems however that old is less of an issue.

From the color dummies, black coat color was found to affect sheep price negatively and significantly. Hence, black colored sheep received a price discount of about $15 \%$ as compared to red coat colored sheep. The negative premium the black coated sheep received emanates from the fact that people tend to avoid black coated sheep or any other livestock (see e.g., Kassie et al, 2009) for two reasons. First, the tsetse fly - the vector for sleeping sickness (trypanosomiasis) - attacks black coated livestock more? than others. Second, red or other lighter colored sheep are preferred to others for purposes of ceremonial slaughtering in the study area. Whitish and creamy white (locally called dallecha) coat colors of traded sheep attracted a $14 \%$ and $6.3 \%$ price premium respectively, compared to red coat color, ceteris paribus. Body size was another trait of sheep that significantly affected price of sheep. Intuitively, sheep with a large body size receive higher prices and hence sheep with a large body size were found to fetch about $15.8 \%$ higher price premium compared with small sized sheep. Sheep with thin and long tail and thin and medium length tail received $8 \%$ and $11.53 \%$ less price, respectively, compared to long and fat tailed sheep.

The determinants of sheep price other than traits of sheep were market location and seasonal factors. Sheep command a significantly higher price in season one (Christmas season) compared with season two (normal season). The Christmas season is the period of high demand for sheep (or livestock in general) that overlaps the crop produce harvesting season that might increase farmers' (as sheep sellers) bargaining power as they can postpone selling when prices are not right. In season one sheep will attract an $8 \%$ higher price premium compared to selling in season two. This a general tendency in Ethiopian livestock - particularly small ruminants - marketing as sheep or goat slaughtering is an indispensable part of big festivities such as Christmas provided they are affordable.

Among the market location dummies, sheep in Harato attracted a lower price compared with Shambu. This is likely due to the relatively high potential for sheep population in the Harato area and hence high supply. These results imply that smallholder sheep keepers would benefit if they carefully choose the selling time and the market.

The type of buyer was also an important determinant of price paid for sheep in the study area. Farmer-traders (farmers who do par-time trading) paid a lower price as compared to other groups of buyers. This is possibly because these buyers are well informed both about the production and the marketing of sheep such that they would be in a better position to bargain for a lower price.

In summary, the estimation results show that traits of sheep are much more important determinants of actual price observed than types of buyers and sellers or purposes of buying and selling. Among the attributes considered, age, black coat, large body size, and tail condition were found to be most influential in determining the price paid for sheep in the study area. 


\section{Conclusions}

This study generated primary data on actual transactions accomplished in four rural markets over three months in central Ethiopia. Using the revealed preference analysis framework and hedonic price modeling, the study determined the level of influence of attributes of sheep and features of buyers and sellers in sheep markets on actual prices paid per head of sheep. As heteroscedasticity is common in cross-sectional data and small sample data, alternative estimations, mainly heteroscedasticity consistent formulations, were employed in addition to OLS estimation.

This estimations have shown how intricate are the relationships between price and traits of sheep and trait and trait level identification of sheep consumers in the rural areas of the study areas. Traits such as age, black coat, large body size, and tail condition were found to be most influential in determining the revealed preferences and hence the prices paid in these rural markets.

Factors such as season of marketing, market location, and type of buyer were also found to be highly important in influencing the prices paid for sheep. The significance of season and market place in influencing price paid for sheep as well justifies the need of targeting season and market places so that smallholder sheep keepers could benefit from the required transformation in the sheep production system. Alternatively or even additionally, linking producers to urban markets where there is high demand for sheep would be an important step to improve farmers' return from the system.

Two important implications can be drawn from the results of this study. First, the consumption of sheep in these areas seem to be very sophisticated such that an intervention that focuses on a single attribute would hardly be successful to improve both supply and demand sides of sheep marketing in the study area. Second, the sheep genetic resources in areas similar to the study areas need to be comprehensively profiled for their attributes. This would be essential in identifying the important attributes of the existing stock and hence prioritizing those traits that need to be improved both for biological and economic efficiency.

Competing interests

The authors declare that they have no competing interests.

Authors' contribution

ZG carried out data collection and supervised enumerators, participated in developing survey instrument, participated in statistical analysis and interpretation of results, participated in designing of the study, and drafted the manuscript. GT participated designing the study, helped in survey instrument development, participated in statistical analysis, and helped in finalizing the draft manuscript. AH participated in designing of the study, helped in preparing survey instrument mainly on identifying sheep trait and categorising these traits as it could be meaningful to researchers in sheep breeding and understandable to respondents. He also helped in editing interpretation of results. DB participated in data analysis and interpretation, and helped in shaping the draft paper.

\section{Acknowledgements}

The authors are grateful to ILRI-ICARDA-BOKU project for funding this research. This paper has benefited immensely from insightful comments of an anonymous reviewers and editor of the Agricultural and Food Economics and the authors are very grateful for comments and suggestions received. Yet, the authors alone are responsible for the contents of the paper.

Author details

${ }^{1}$ The University of Liverpool, Liverpool, UK. ${ }^{2}$ ICARDA, Aleppo, Syria. ${ }^{3}$ ILRI, Nairobi, Kenya. ${ }^{4} \mathrm{CIMMYT}$, Harare, Zimbabwe.

Received: 19 December 2012 Accepted: 8 July 2013

Published: 20 Aug 2013

References

Abdulai A (2000) Spatial Price Transmission and Asymmetry in the Ghanaian Maize Market. Journal of Development Economics 63:327-349 
Anglin PM, Gencay R (1996) Semiparametric Estimation of a Hedonic Price Function. Journal of Applied Econometrics 11:633-648 Barret CB, Chabari F, Bailey D, Little P, Coppock D (2003) Livestock Pricing in the Northern Kenyan Rangelands. Journal of African Economies 12(2):127-155

Barret C, Mutambatsere E (2007) Agricultural Markets in Developing Countries. Entry. In: Durlauf SN, Blume LE (eds) The New Palgrave Dictionary of Economics, 2nd edn. Palgrave McMillan, London

Champ PA, Boyle KJ, Brown TC (eds) (2003) A Primer on Nonmarket Valuation. Kluwer Academic Press, Dordrecht

Chang J, Lusk J, Norwood F (2010) The Price of Happy Hens: A Hedonic Analysis of Retail Egg Prices. Journal of Agricultural and Resource Economics 35(3):406-423

Cropper ML, Deck LB, McConnel KE (1988) On the Choice of Functional Form for Hedonic Price Functions. Rev Econ Stat 70(4):668-675

CSA (Central Statistical Agency) (2009) Statistical Abstract. Addis Ababa, Ethiopia

CSA (Central Statistical Agency), (2007) Statistical Abstract. Addis Ababa, Ethiopia

Davidson R, MacKinnon JG (1993) Estimation and Inference in Econometrics. Oxford University Press, Cambridge

Drucker AG, Gomez V, Anderson S (2001) The economic valuation of farm animal genetic resources: A survey of available methods. Ecol Econ 36:1-18

Ekeland I, Heckman JJ, Nesheim L (2004) Identification and Estimation of Hedonic Models. Journal of political economy 112(1): s60-s109

FAOSTAT (2009) FAO (Food and Agricultural Organization of the United Nations), Rome., http://faostat.fao.org. Accessed 19 October

FAOSTAT (2010) FAO (Food and Agricultural Organization of the United Nations), Rome., http://faostat.fao.org. Accessed 23April

Faustin V, Adegbidi AA, Garnett ST, Koudande DO, Agbo V, Zander KK (2010) Peace, health or fortune?:Preferences for chicken traits in rural Benin. Ecol Econ 69(9):1848-1857

Gezahegn A, Mohammad AJ, Hailemariom T, Elias M, Getahun K (2006) Seasonal and Inter-Market Differences in Prices of Small Ruminants in Ethiopia. Journal of Food Products Marketing 12(4):59-77

Haab TC, McConnel KE (2002) Valuing Environmental and Natural Resources: The Econometrics of Non-Market Valuation. Edward Elgar, Cheltenham, UK, Northampton, MA, USA

Hensher D, Rose J, Greene W (2005) Applied Choice Analysis: A Primer. Cambridge University Press, Cambridge Jabbar MA, Diedhiou ML (2003) Does Breed Matter to Cattle Farmers and Buyers? Evidence from West Africa? Ecol Econ 45:461-472

Kassie GT (2007) Economic Valuation of the Preferred Traits of Indigenous Cattle in Ethiopia. Christian Albrechts University of Kiel, Kiel, Germany, PhD Dissertation. pp, 177

Kassie GT, Abdulai A, Wollny C (2009) Valuing Traits of Indigenous Cows in Central Ethiopia. Journal of Agricultural Economics 60(2):386-401

Kassie GT, Abdulai A, Wollny C (2011a) Heteroscedastic Hedonic Price Model for Cattle in the Rural Markets of Central Ethiopia. Applied Economics 43(24):3459-3464

Kassie GT, Abdulai A, Wollny C, Ayalew W, Dessie T, Tibbo M, Haile A, Mwai O (2011b) Implicit prices of indigenous cattle traits in central Ethiopia: Application of revealed and stated preference approaches. ILRI Research Report 26. CIMMYT and ILRI, University of Kiel

Lancaster K (1966) A new approach to consumer theory. Journal of Political Economy 74:132-157

Long JS, Ervin LH (2000) Using Heteroscedasticity Consistent Standard Errors in the Linear Regression Model. The American Statistician 54(3):217-224

MacKinnon JG, White H (1985) Some Heteroscedasticity Consistent Covariance Matrix Estimators with Improved Finite Sample Properties. Journal of Econometrics 29(3):305-325

Negassa A, Jabbar M (2008) Livestock ownership, commercial off-take rates and their determinants in Ethiopia. Research Report 9. ILRI (International Livestock Research Institute), Nairobi, Kenya, p 52

Nesheim L (2006) Hedonic price functions. Centre for microdata methods and practice working paper CWP18/06

Oczkowski E (1994) A Hedonic Price Function for Australian Premium Table Wine. Australian Journal of Agricultural Economics 38:93-110

Omondi I, Baltenweck I, Drucker AG, Obare G, Zander KK (2008) Economic valuation of sheep genetic resources: implications for sustainable utilization in the Kenyan semi-arid tropics. Trop Anim Health Prod 40(8):615-626

Palmquist RB (2006) Property Value Model. In: Maler KG, Vincent J (eds) Handbook of Environmental Economics, Edition 1, 2nd edn., pp 763-819

Parmeter CF, Henderson DJ, Kumbhakar SC (2007) Nonparametric Estimation of a Hedonic Price Function. Journal of Applied Econometrics 22:695-699

Richards TJ, Jeffrey SR (1996) Establishing indices of genetic merit using hedonic pricing: an application to dairy bulls in Alberta. Canadian journal of Agricultural Economics 44:251-264

Rosen S (1974) Hedonic Prices and Implicit Markets: Product Differentiation in Pure Competition. Journal of Political Economy 82(1):34-35

Satimanon T, Weatherspoon D (2010) Hedonic Analysis of Sustainable Food Products. International Food and Agribusiness Management Review 13(4):57-74

Scarpa R, Kristjanson P, Ruto E, Radeny M, Rege JEO (2003) Valuing indigenous cattle breeds in Kenya: an empirical comparison of stated and revealed preference value estimates. Ecol Econ 45:409-426

Tibbo M (2006) Productivity and health of indigenous sheep breeds and crossbreds in the Central Ethiopian highlands, PhD Thesis, Swedish University of Agricultural Sciences. Sweden University Press, Uppsala

Williams OT, Okike I, Spycher B (2006) A Hedonic Analysis of Cattle Prices in the Central Corridor of West Africa: Implications for Production and Marketing Decisions. In: Contributed paper prepared for presentation at the International Association of Agricultural Economists Conference. Gold Coast, Australia

10.1186/2193-7532-1-6

Cite this article as: Terfa et al:: Valuation of traits of indigenous sheep using hedonic pricing in Central Ethiopia. Agricultural and Food Economics 2013, 1:6 